RECENT PROGRESS

\title{
Dual Dorsal Columns: A Review
}

\author{
CHARLES H. M. BECK
}

SUMMARY: Recent evidence indicates that Wall (1970) may have been premature in concluding that dorsal column lesions produce no discernable sensory defects. Much of the negative evidence Wall presented to support this view is inconclusive. In addition several studies have reported significant sensory deficits in animals with severed dorsal columns. On the other hand, the literature strongly supports Wall's view that dorsal column lesions cause motor disturbances. A review of the anatomical and electrophysiological literature reveals growing evidence for the dissociation of two major subsystems relaying in the dorsal column nuclei. The possible functions of these two systems are discussed.

RESUME: Une démonstration récente indique que Wall (1970) semble avoir conclu prématurément que des lésions à la colonne dorsale ne produisent aucune défectuosité sensorielle. Une grande partie de l'évidence négative que Wall a présentée pour soutenir cette idée n'est pas concluante. De plus plusieurs recherches rapportèrent des diminutions sensorielles significatives chez des animaux dont la colonne dorsale était endomagée, D'autre part, la litterature supporte le point de vae de Wall à savoir que des lésions à la colonne dorsale engendrent des désordres d'ordre moteur. Une revue de la litterature en anatomie et en électrophysiologie révèle une preuve grandissante en faveur de la dissociation de deux sous-systèmes majeurs reliant les noyaux de la colonne dorsale. Les fonctions de ces deux systèmes sont discutées ici.

Reprint Requests to: Charles H. M. Beck, Department of Psychology, Biological Sciences Bldg., University of Alberta, Edmonton, Alberta T6G 2E1.

Presented to the combined meeting of the Alberta Neurological Society and the Canadian Prairie Chapter of the Society for Neuroscience in October. 1975.

Supported by a grant from the Medical Research Council of Canada.

From the Neuropsychology Unit, Department of Psychology, University of Alberta, Edmonton, Alberta.
Wall (1970) disputed the classical view of dorsal column function, namely that the dorsal columns are necessary for somesthetic discrimination of weight, joint position, vibration, tactual localization, tactual acuity and roughness discrimination. He concluded after a survey of the largely negative findings in the literature that no sensory defect followed isolated dorsal column lesions. Wall's subsequent review (Wall and Dubner, 1972) did not lead him to alter this judgement. Other reviewers have agreed that it is very difficult to observe any behavioral deficits after such lesions (Brown, 1973); that it is difficult to come to any firm conclusions about dorsal column function (Lynn, 1975) or that the behavioral impairments are transient (Semmes, 1973). In this paper evidence will be summarized supporting a re-evaluation of the negative data and suggesting that there are lasting sensory deficits following dorsal column lesions. Next, the literature bearing on Wall's (1970) other conclusions will be reviewed and finally, anatomical and electrophysiological evidence will be gathered to provide an hypothesized physiological substrate for the behavioral deficits.

\section{Criteria For Negative Evidence}

Failure to find a lasting sensory deficit following dorsal column insult depends on the completeness of the interruption of the dorsal columns. Geschwind's (1974) review emphasized the amazing capacity of the central nervous system for compensation following injury. Significant sparing of visual function occurs after destruction of 98 percent of the fibers of the optic tract in cats (Galambos et al., 1967). No deficits were observed on several reaction time tests and tests of reaching accu- racy if less than 80 percent of the fibers of the medullary pyramids of monkeys were interrupted (Beck and Chambers, 1970). Only dorsal column lesions interrupting more than 90 percent of the fibers caused tactile roughness discrimination deficits and altered somatosensory cortical evoked potentials in cats (Dobry and Casey, 1972a; 1972b). The authors suggested that Kitai and Weinberg (1968) failed to observe a permanent impairment in tactile roughness discrimination in cats because the Kitai and Weinberg lesions severed only 80 percent of the fibers of the dorsal columns. The mechanism by which labelled line systems such as the pyramidal tract, optic tract and dorsal columns maintain functional resilience inspite of almost total destruction is unexplained. Reorganization of remaining connections undoubtedly plays some part (Geshwind, 1974; Wall and Egger, 1971). In any case, studies which do not specifically report that at least 90 percent of the dorsal column fibers were destroyed are of questionable value if the results fail to reject the null hypothesis.

A distinction should be made between negative evidence based on high cervical, as opposed to thoracic level, dorsal column lesions. Whitsel et al., (1972) have reviewed evidence that although hindlimb projections bearing signals from joint, muscle and skin enter the fasciculus gracilis, all except the fast adapting, cutaneous, leave the dorsal columns at the low thoracic level. Apparently kinesthetic cuneate fibers do not leave the cuneate fasciculus, but remain in the dorsal columns (Uddenberg, 1968). This distinction between fore and hindlimb representation in the dorsal columns is reinforced by neurological observations 
that the cervical level dorsal column lesion deficits are more severe in the forelimbs than in the hindlimbs (Gilman and Denny-Brown, 1966). In sum, negative findings on hindlimb function following thoracic dorsal column lesions should not be assumed to be paralleled by forelimb sparing of the same function following cervical level insult.

Lastly, absence of sensory defects on a test employing ill defined polymodal stimuli which can be conveyed by pathways other than the dorsal columns are of meager interpretable value.

\section{Sensory Defects}

Wall (1970) concluded from his review that no sensory defect had been shown to follow isolated dorsal column lesions. He cited ten articles as providing negative results after dorsal column section. Of these ten, only one is admissable if the above criteria are applied. One study (Cook and Browder, 1965) is rejected because no histology was done. This exclusion includes the negative results on one of those patients presented in Wall's (1970) paper. Four other studies report that histology was done, but did not specify the degree of sparing (Christiansen, 1966; Levitt and Schwartzman, 1966; Schwartzman and Bogdonoff, 1968; Vierck, 1966). In one study the lesions did not sever more than 80 percent of the dorsal column fibers (Kitai and Weinberg, 1968). Diamond et al., (1964) used subcutaneous electrical stimulation as a conditioned stimulus on an avoidance task. The description of the electrodes and the stimulation parameters suggests the probable elicitation of pain and deep tissue sensations which may ascend pathways other than the dorsal columns (Applebaum et al., 1975; Nashold et al., 1972). And finally, two studies by Norrsell (Lundberg and Norrsell, 1960; Norrsell, 1966) involved thoracic dorsal column lesions and so the negative results are not applicable to forelimb, dorsal column function.

The only remaining negative results study on sensory defects in Wall's (1970) list is the DeVito et al.,
(1964) failure to find a permanent deficit in weight pulling discrimination following complete cervical dorsal column section in monkeys. It is concluded that Wall (1970) overstated his case in claiming that no sensory deficits appear after dorsal column lesions.

What about negative results published after Wall's (1970) review? Tapper's (1970) beautiful evaluation of the tactile pad sensibility after dorsal column lesions in cats found no sensory impairment. However, the lesions were made at the thoracic level and were incomplete. Schwartzman and Bogdonoff (1969) failed to find a lasting alteration in monkey proprioception and vibration discrimination after thoracic dorsal column lesions. Schwartz et al., (1972) obtained insignificant effects following cervical level, dorsal column lesions in monkeys on a variety of tactual tasks including localization of wrist shock, roughness and shape discriminations. All lesions spared some dorsal column fibers. Dorsal column sparing was also evident in a study in which no effect of cervical dorsal column sectioning was observed on somatic cortical evoked potentials in monkeys (Eidelberg and Woodbury, 1972).

In summary, the negative evidence provides information about recovery of function after partial, dorsal column destruction and thoracic level lesion effects but nothing about the effects of complete, cervical level, dorsal column section on forelimb sensation. No one has yet tested two point tactual thresholds, tactual localization, vibration thresholds or joint movement discrimination in the forelimb after demonstrating complete severing of the cervical dorsal columns. Mountcastle (Mountcastle and DarianSmith, 1968) could be correct after all in suggesting that the dorsal columns are important for these functions.

Evidence reinforcing this view comes from the positive findings of sensory defects by Dobry and Casey (1972a; 1972b) mentioned above and by Vierck $(1973 ; 1974)$. Cervical level, dorsal column lesions in cats caused impairment of tactual rough- ness discrimination and alteration of peripherally elicited somatic cortical evoked potentials (Dobry and Casey, 1972a; 1972b). Bilaterally complete, thoracic, dorsal column lesions in macaques resulted in impaired tactual size discrimination of discs pressed against the feet. The impairment was still present after one year of testing (Vierck, 1973). A similarly enduring inability was observed in a similar preparation on a test of discrimination of direction of tactile stimulus motion (Vierck, 1974). It is difficult to explain the difference between the results of Vierck (1973) and Schwartz et al., (1972) unless dorsal column fiber sparing is taken into account.

Wall's (1970) second conclusion was, "sensory defects have been observed when lesions of the dorsal columns are combined with lesions of the other tracts". The recent literature gives no reason to question Wall's judgement on this point (Lynn, 1975).

Thirdly, Wall (1970) stated that "when the dorsal columns are left intact, but all other tracts are cut, no behavioral responses to any stimuli are seen". This was based on Wall's observation of the failure to orient to hindleg stimulation by rats with thoracic level lesions. Only one study has direct bearing on this issue. Electrical stimulation of peripheral nerve afferents from the cats' hindlimb may be used by the cat as an operant stimulus on a food rewarded lever press task, even after cutting all cord tracts except the thoracic dorsal columns (Myers et al., 1975). The authors felt that Wall was not justified in stating that isolated dorsal column activity could not be consciously perceived. This disagreement may be resolved as a species' difference, as a difference in stimuli, as a difference in the time of postoperative testing or as a difference in the degree of preoperative training. Corroborative evidence for the view of Myers et al., (1975) comes from the subjective reports of paresthesia by humans receiving electrical stimulation of the dorsal columns for the relief of pain (Larson et al., 1974; Nashold et al., 1972). However, since the dorsal 
columns were not isolated one would expect transynaptic activation of other cord pathways as is indeed the case (Bantli et al., 1975). Thus, such evidence is not conclusive even when needle electrodes rather than the usual disc electrodes are used (Hosobuchi et al., 1972).

\section{Movement Associated Effects}

Wall (1970) concluded in his review that "particular types of motor deficits follow dorsal column section'. Although he did not acknowledge it, Wall was in good company in this judgement. "Dorsal column lesions produce a marked disability in the motor sphere. The limbs make poorly directed flailing movements, there is a loss of projected movement in space which is more marked in the upper than in the lower limbs," (Mountcastle and DarianSmith, 1968). The literature since Wall's (1970) review bears out Wall and Mountcastle.

Increased escape latencies in monkeys to near threshold shocks to the hindlimbs were observed after thoracic dorsal column lesions (Vierck et al ., 1971). Cats with cervical, dorsal column lesions were impaired in accuracy in tracking and in searching when jumping to moving targets (Dubrovsky and Garcia-Rill, 1973). Cats exhibited impaired performance after cervical, dorsal column lesions while walking and turning on a narrow beam, while jumping onto a rotating turntable (Melzack and Bridges, 1971) and in jumping over barriers while running on a moving conveyor belt (Melzack and Southmayd, 1974). Inability to catch a falling bait by squirrel monkeys with cervical, dorsal column lesions was reported by Beck (in press). Macaques with similar lesions have permanently impaired manual dexterity (Vierck, 1973). Macaques were able to retrieve bait from a rotating turntable twice as readily preoperatively as after cervical, dorsal column lesions (Schwartz et al., 1972). The sparing from deficit of forelimb movements in personal as opposed to extrapersonal space by monkeys after dorsal column lesions (Gilman and Denny-Brown, 1966) has not been verified (Wall and
Dubner, 1972). Finally, the firing of cells in the dorsal column nuclei is inhibited just prior to voluntary movement in cats (Coulter and Thies, 1971; Ghez and Lenzi, 1971; Ghez and Pisa, 1972) and in rats (O'Keefe and Gaffan, 1971).

In summary, dorsal column impulses do reach conscious levels and interrupting their flow in the cord produces sensory as well as movement associated deficits. Vierck (1974) emphasized that the impairment in the discrimination of direction of tactual stimulation by monkeys was not a motor deficit because the stimuli were passively received by the animal. What are the possible explanations for the motor and sensory deficits? Perhaps the sensory and motor deficits simply result from malfunction in different sense modalities. Perhaps in the case of sensory loss, impairment of the cutaneous system is salient and in the motor disturbances, joint and muscle impairments are preeminent. Another possibility is that the two types of deficits reflect not only differences in peripheral input, but also differences in central targets According to this hypothesis, the dorsal columns do not represent a unitary system but at least a dual system. The sensory component receives mainly cutaneous inputs and projects to cutaneous brain structures and the movement system receives primarily kinesthetic stimuli and sends fibers to motor structures in the brainstem and cerebrum. The following review summarizes the anatomical, electrophysiological and behavioral evidence for the existence of such a duality. For the purposes of this review, unless otherwise specified, the species studied is the cat. Unless stated to the contrary, the data on nucleus gracilis and nucleus cuneatus are not in conflict.

\section{Dorsal Column Nuclei \\ Architecture}

The gracile and cuneate nuclei may be divided into two zones in the rat (Basbaum and Hand, 1973) and cat (Hand, 1966; Keller and Hand, 1970; Kuypers and Tuerk, 1964; Taber, 1961). Beginning just below the obex, the caudal zone, hereinafter referred to as caudal dorsal column nuclei or caudal DCN, contains large, $20 \mu \mathrm{m}$ diameter, rounded cells with short bushy dendrites. The clustering of the cells into nests or bricks is easily seen under the light microscope. Degenerating dorsal root fiber terminals form bands or lines coinciding with the location of the cell clusters of the caudal region (Basbaum and Hand, 1973; Keller and Hand, 1970).

By contrast the cells of the rostral zone and the ventral portion of the caudal zone, hereinafter referred to as the rostral DCN, are smaller, $12 \mathrm{x}$ $8.5 \mu \mathrm{m}$, and irregular in shape, with long sparse dendrites. These cells are scattered rather than clustered and this is reflected in the dispersion of the degenerating dorsal root terminals in the rostral DCN (Basbaum and Hand, 1973; Keller and Hand, 1970; Rustioni and Macchi, 1968). Some authors prefer to include the caudal tip of the caudal zone in the "rostral" zone and some would prefer to assign the caudal tip to a third zone (Berkley, 1975). I prefer the former.

\section{Dorsal Column Nuclei \\ Cell Characteristics}

Caudal DCN cells in the rat tend to have a low threshold to stimulation, short latency responses to peripheral stimulation, and are able to follow high frequency stimulation whereas rostral DCN cells have a broader range of thresholds, longer latencies and are less able to follow high frequency stimulation (McComas, 1963). Caudal DCN cells are faster adapting (Petit and Burgess, 1968) and less susceptible to anesthetics than rostral DCN cells (Gordon and Paine, 1960; McComas, 1963).

\section{Adequate Stimuli For DCN Cells}

Caudal DCN cells exhibit stimulus specificity whereas rostral DCN cells, in the majority of cases, respond to more than one type of peripheral stimulus (Gordon and Jukes, 1964a). Units sensitive to hair movement, cutaneous pressure and deep pressure have been found in both rostral and caudal DCN (Gor- 
don and Jukes, 1964a; Petit, 1972; Perl et al., 1962; Rosen, 1969). However, the concentration of hair units is greatest in the caudal zone (Perl et al., 1962; Winter, 1965). Claw movement units appear only in the caudal DCN (Gordon and Jukes, 1964a) and units sensitive to heat exchange and tissue injury are found only in the rostral DCN (Perl et al., 1962; Petit, 1972). While joint position (Kuhn, 1949; Perl et al., 1962; Winter, 1965), and muscle spindle activation (Rosen, 1969) definitely appear in the rostral DCN, far fewer cells responding to such stimuli are found in the caudal DCN (Rosen, 1969; Rosen and Sjolund, 1973; Winter, 1965).

\section{Organization of DCN Cells}

The units in both caudal and rostral zones have a somatotopic organization related to peripheral innervation density (Gordon and Jukes, 1964a; Keller and Hand, 1970; Winter, 1965). However, the rostral DCN units are organized for more overlapping of body segments compared to the discrete somatotopic arrangement of the caudal DCN units (Gordon and Jukes, 1964a; Keller and Hand, 1970). Stimulation of adjacent peripheral receptive fields produces surround inhibition in caudal DCN cells and surround facilitation in rostral DCN cells (Gordon and Jukes, 1964a). The receptive fields of caudal DCN units are smaller, have less overlap and represent only the contralateral somatic surface whereas the receptive fields of the rostral DCN cells are wider, have more overlap with each other and derive from the ipsilateral as well as the contralateral body surface (Blum and Whitehorn, 1973; Gordon and Jukes, 1964a; Gordon and Paine, 1960; McComas, 1963; Perl et al., 1962). However, Winter (1965) found that receptive field size related only to peripheral zone of representation and not to the location of the cell within the DCN. The proportion of the nuclei devoted to the distal limb is greater than that of the proximal body structures in the caudal region of the $\mathrm{DCN}$. The opposite is true in the rostral region (Keller and Hand, 1970). It is worth noting that the gracile nucleus, cuneate nucleus and the nucleus of the spinal tract of the fifth cranial nerve when taken together form a complete representation of the cat's body (Keller and Hand, 1970). A problem beyond the scope of this paper is whether the nucleus of the spinal tract of the fifth cranial nerve shows the same duality.

\section{Ascending Pathways}

\section{Associated With The DCN}

Although all of the ascending fibers terminating in the caudal DCN are carried in the dorsal columns, and all are primary afferents, many of the fibers ending in the rostral DCN ascend the dorsolateral funiculi and many are secondary afferents (Petit, 1972; Rustioni, 1973; Rustioni, 1974; Rustioni and Molenaar, 1975). Whitsel et al., (1972) have proposed that in the case of the squirrel monkey fasciculus gracilis, only fast adapting cutaneous fibers continue all the way up the dorsal columns. The fast adapting cutaneous fibers from the hindlimbs ascend fasciculus gracilis to the caudal gracile nucleus. Ascending fibers from gracile nucleus send axons via the medial lemniscus to the core of VP thalamus and from there cells project to areas 3 and 1 of the postcentral gyrus. Muscle afferents from the hindlimbs enter fasciculus gracilis, but then leave the dorsal columns to synapse with cells of the dorsal horn at the thoracolumbar border. These cells send axons up the dorsolateral funiculi to terminate in the gracile nucleus and nucleus $\mathrm{Z}$ of the lower medulla. The cortically bound impulses then continue up the medial lemniscus to the border zone of VP thalamus and thence to area $3 \mathrm{a}$ of the neocortex. A similar dorsolateral route to that of muscle afferents is postulated for joint afferents. The impulses in this pathway ascend to Brodmann's area 2 (Whitsel et al., 1972). The authors do not describe the zones of the gracile nucleus in which these pathways relay. Supporting evidence for dissociable rostral and caudal DCN projections up the medial lemniscus is presented by Kuypers and Tuerk (1964). These authors observed fiber degeneration in the lateral and medial portions of the medial lemniscus following lesions of the caudal and rostral DCN respectively. The terminations of the rostral and caudal DCN are distinguishable at the thalamic level. Fiber terminal degeneration in the thalamus is more dense and is arranged in discrete clusters following caudal DCN lesions. Comparable lesions in the rostral DCN produced more scattered patterns of terminal degeneration in the thalamus (Hand and Van Winkle, 1975). The caudal part of the cuneate nucleus projects to rostral and middle VPL medialis and the caudal part of the gracile nucleus sends fibers to VPL lateralis. The rostral DCN projects to the whole of VPL (Groenewegen et al., 1975; Hand and Van Winkle, 1975). In addition, rostral DCN cells send fibers to the magnocellular portion of the medial geniculate body, the posterior group of thalamic nuclei, zona incerta, the dorsal accessory olive, the tectum, the pretectum and the cerebellar cortex (Berkley, 1975; Boivie, 1974; Cooke et al., 1971; Gordon and Seed, 1961; Groenewegen et al., 1975; Hand and Van Winkle, 1975; Lund and Webster, 1967 in the rat; Rinvik and Walberg, 1975). The posterior thalamic nuclei project to the basal ganglia and the association cortex (Graybiel , 1972).

\section{Descending Pathways \\ Associated With The DCN}

Dense fiber terminal degeneration was observed in the rostral region of the dorsal column nuclei following cortical SI lesions whereas only sparse degeneration was seen in the caudal zone (Kuypers and Tuerk, 1964). Many reports have been published on the effects of cortical stimulation on DCN unit responses. See the reviews by Kruger (1973) and Towe (1973). Pyramidal tract stimulation altered the firing rates of 70 percent of the rostral and 35 percent of the caudal units studied (Erulkar et al., 1966; Winter, 1965). Postcruciate cortex stimulation inhibits the firing of caudal DCN cells and facilitates the activity of rostral 
zone cells (Gordon and Jukes, 1964b).

\section{Behavioral Effects of}

DCN System Lesions

There are no reports in the literature of the behavioral effects of lesions restricted to the rostral or caudal zones of the dorsal column nuclei or their respective efferents and afferents. Melzack and Bridges (1971) observed less disruption of motor performance in cats after lesioning both DCN zones compared to the deficits after dorsal column cervical lesions. Ferraro and Barrera (1935b) came to a similar conclusion after observing macaque motor impairment after similar lesions.

\section{Species' Differences}

Before concluding it would be appropriate to make some general comments about differences between species. Except where stated otherwise all studies reviewed were performed with cats. This indicates an obvious lack of anatomical and electrophysiological data pertaining to other species especially monkeys and apes. The only study on primate dorsal column nuclei cytoarchitecture fails to mention dorsal or rostral zones. However, a medial zone composed of cells grouped in concentric laminations was discriminated from a lateral zone with smaller, scattered triangular cells (Ferraro and Barrera, 1935a). Dorsal column cell responses to cortical stimulation in the monkey are quite different from those in the cat, but the precise differences relative to the two zones are not discernable from the date provided (Towe, 1973).

The same behavioral tests do not necessarily produce similar effects in different species following dorsal column lesions. Cervical, dorsal column lesions in cats cause the cat to stumble and fall when jumping to a moving turntable (Melzack and Bridges, 1971) but have no observable effect on squirrel monkeys with similar lesions (Beck, 1973). Nor do operated squirrel monkeys exhibit forelimb ataxia when reaching into extrapersonal space (Beck, in press), as do macaques (Gilman and Denny-Brown, 1966). Such differ- ences may eventually be described in terms of the evolution of alternative neural mechanisms and the behavioral specialization resulting from adaptation to a particular ecological niche (Beck, in press).

\section{General Conclusions}

If it is true that the rostral DCN system receives mainly muscle and joint information, as well as heavy corticofugal input and projects to such structures as the inferior olive, pretectum, tectum, cerebellum and secondarily the basal ganglia, the possibility of involvement in movement associated functions becomes apparent. One would predict anticipatory failures of the type observed by Melzack and Southmayd (1974) in cats and by Beck (in press) in monkeys after rostral DCN but not after caudal DCN lesions. Conversely, one would expect deficits in discrimination of passively received, tactual, directional stimuli (Vierk, 1974) after caudal but not after rostral zone lesions. Speculative support for such a double dissociation has appeared in the anatomical literature. Kuypers and Tuerk (1964) have suggested that the rostral DCN may be involved in the anticipation of movement produced sensation whereas the caudal zone may be specialized for high spatial resolving power. Basbaum and Hand (1973) stated that sensory motor integration and spatial discrimination were the likely functions of the rostral and caudal DCN respectively.

In a more sweeping review of auditory, visual and somatic systems, Graybiel (1972) hypothesized a duality of main line versus adjunct systems within each sensory modality. Graybiel's lemniscal line system corresponds to the classical dorsal column-medial lemniscal system and the caudal DCN system of this paper. Graybiel believes that this system is involved in the spatial and temporal resolution of stimuli. By contrast, Graybiel's somatic adjunct system projects to the posterior thalamus and from there to the basal ganglia and association cortex. The adjunct system of Graybiel is postulated to coordinate the relevant flow of sensory information with motor instructions for current or impending movements. Perhaps impairment in anticipation or in rapid processing of movements already observed after dorsal column lesions (Beck, in press; Dubrovsky and Garcia-Rill, 1973; Melzack and Bridges, 1971; Melzack and Southmayd, 1974) is related through Graybiel's adjunct system to the demonstration of single unit firing to anticipated movement. Such activity has been recorded in the monkey posterior parietal association cortex (Mountcastle et al., 1975). If this is so, the mild neglect noted after dorsal column lesions in monkeys (Schwartzman and Bogdonoff, 1968; 1969) may be related by a common physiological mechanism to the more robust neglect seen after parietal association cortex lesions (Ettlinger and Kalsbeck, 1962).

One should question whether the duality suggested here for the dorsal columns extends to other somesthetic pathways. Graybiel (1972) has proposed a similar spinothalamic duality on anatomical grounds. Semmes' (1969) review suggested a dissociation of topographic and nontopographic systems incorporating all pathways within the somesthetic modality. The distinguishing anatomical and electrophysiological features of her two systems are very similar to those derived in this review. The properties of the Semmes' topographic system correspond to those of the caudal DCN system, and those of the nontopographic system to those of the rostral DCN system. The major revision is the splitting of the DCN system into two components. No one has examined the effects of lesions of spinal cord pathways, other than the dorsal columns, on tasks involving motor anticipation or discrimination of directional stimuli. One might expect from Semmes' account that neospinothalamic lesions and spinocervical tract lesions would augment caudal DCN zone lesion effects, whereas lateral spinothalamic lesions would augment rostral DCN lesion effect. Eidelberg and Schwartz (1971) noted that DC lesions exaccerbated neglect induced by neospinothalamic lesions. How- 
ever, the likelihood that spinothalamic lesions will produce a deficit on the discrimination of the direction of movement of tactual stimuli or discrimination of Pacinian sensibility is contraindicated by Willis et al., (1975). The authors found no evidence of directionally sensitive units or of Pacinian corpuscle input to units of the spinothalamic tract in monkeys.

\section{REFERENCES}

APPLEBAUM, A. E., BEALL, J. E., FOREMAN, R. D. and WILLIS, W. D. (1975). Organization and receptive fields of primate spinothalamic tract neurons. Journal of Neurophysiology 38, 572-586.

BANTLI, H., BLOEDEL, J. R. and THIENPRASIT, P. (1975). Supraspinal interactions resulting from experimental dorsal column stimulation. Journal of Neurosurgery 42, 296-300.

BASBAUM, A. I., and HAND, P. J. (1973). Projections of cervico-thoracic dorsal roots to the cuneate nucleus of the rat with observations on cellular bricks. Journal of Comparative Neurology 148, 347-360.

BECK, C. (1973). Compensation of postural control by squirrel monkeys following dorsal column lesions. Advances in Behavioral Biology 7, 421-424.

BECK, C. (in press). Forelimb performance by squirrel monkeys (Saimiri sciureus) before and after dorsal column lesions. Journal of Comparative and Physiological Psychology.

BECK, C. H. and CHAMBERS, W. W. (1970). Speed, accuracy and strength of forelimb movement after unilateral pyramidotomy in rhesus monkeys. Journal of Comparative and Physiological Psychology 70 , part $2,1-22$.

BERKLEY, K. J. (1975). Different targets of different neurons in nucleus gracilis of the cat. Journal of Comparative Neurology 163, 285-304.

BLUM, P. and WHITEHORN, D. (1973). Wide-field neurons in the cuneate nucleus of the cat. Federation Proceedings 32, 399.

BOIVIE, J. (1974). Thalamic termination of fibers from the dorsal column nuclei and spinal cord in the macaque. Anatomical Record 178, 313.

BROWN, A. G. (1973). Ascending and long spinal pathways: dorsal columns, spinocervical tract and spinothalamic tract. In "Handbook of Sensory Physiology", volume 2, Somatosensory system edited by $A$. Iggo, Springer-Verlag, Berlin, pp. 315-338.

CHRISTIANSEN, J. (1966) Neurological observations of macaques with spinal cord lesions. Anatomical Record 154, 330.

COOK, A. W. and BROWDER, E. J. (1965). Function of posterior columns in man. Archives of Neurology (Chicago) 12, 72-79.
COOKE, J. D., LARSON, B., OSCARSSON, O. and SJOLUND, B. (1971). Origin and termination of cuneo-cerebellar tract. Experimental Brain Research 13, 339-358.

COULTER, J. D. and THIES, R. (1971). Sensory transmission through the lemniscal pathway during movements and arousal in the cat. Federation Proceedings 30, 664 .

DeVITO, J. L., RUCH, T. C. and PATTON, H. D. (1964). Analysis of residual weight discriminatory ability and evoked potentials following section of dorsal columns in monkeys. Indian Journal of Physiology and Pharmacology 8, 117-126

DIAMOND, I. T., RANDALL, W. and SPRINGER, L. (1964). Tactual localization in cats deprived of cortical areas SI and SII and the dorsal columns. Psychonomic Science 1, 261-262.

DOBRY, P. J. K. and CASEY, K. L. (1972a). Roughness discrimination in cats with dorsal column lesions. Brain Research 44, 385-397.

DOBRY, P. J. K. and CASEY, K. L. (1972b). Coronal somatosensory unit responses in cats with dorsal column lesions. Brain Research 44, 399-416.

DUBROVSKY, B. and GARCIA - RILL, E. (1973). Role of dorsal columns in sequential. motor acts requiring precise forelimb projection. Experimental Brain Research 18, 165-177.

EIDELBERG, E. and SCHWARTZ, A. S. (1971). Experimental analysis of the extinction phenomenon in monkeys. Brain Research 94, 91-108.

EIDELBERG, E. and WOODBURY, C. M. (1972). Apparent redundancy in the somatosensory system in monkeys. Experimental Neurology 37, 573-581.

ERULKAR, S. D., SPRAGUE, J. M., WHITSEL, B. L., DOGAN, S. and JANNETTA, P. J. (1966). Organization of the vestibular projection to spinal cord of the cat. Journal of Neurophysiology 29, 626-664.

ETTLINGER, G. and KALSBECK, J. E. (1962). Changes in tactile discrimination and in visual reaching after successive and simultaneous bilateral posterior parietal ablations in the monkey. Journal of Neurology, Neurosurgery and Psychiatry $25,256-268$.

FERRARO, A. and BARRERA, S. E. (1935b). Summary of clinical and anatomical findings following lesions in the dorsal column system of macacus rhesus monkeys. Association for Research in Nervous and Mental Disease 15, 371-395.

FERRARO, A. and BARRERA, S. E. (1935a). The nuclei of the posterior funiculi in macacus rhesus. Archives of Neurology and Psychiatry 33, 262-275.

GALAMBOS, R., NORTON, T. T. and FROMMER, G. P. (1967). Optic tract lesions sparing pattern vision in cats. Experimental Neurology 18, 8-25.

GESCHWIND, N. (1974). Late changes in the nervous system: an overview. In "Plasticity and Recovery of Function in the Cen- tral Nervous System" edited by D. G. Stein, J. J. Rosen and N. Butters, Academic Press, New York, pp. 467-508.

GHEZ, C. and LENZI, G. L. (1971), Modulation of sensory transmission in cat lemniscal system during voluntary movement. Pfluegers Archives 323, 273-278.

GHEZ, C. and PISA, M, (1972). Inhibition of afferent transmission in cuneate nucleus during voluntary movement in the cat. Brain Research 40, 145-151.

GILMAN, S. and DENNY-BROWN, D. (1966). Disorders of movement and behavior following dorsal column lesions. Brain 89, 397-418.

GORDON, G. and JUKES, M. G. M. (1964a). Dual organization of the exteroceptive components of the cat's gracile nucleus. Journal of Physiology (London) 173, 263-290.

GORDON, G. and JUKES, M. G. M. (1964b). Descending influences on the exteroceptive organizations of the cat's gracile nucleus. Journal of Physiological (London) 173, 291-319.

GORDON, G. and PAINE, C. H. (1960). Functional organization in nucleus gracilis of the cat. Journal of Physiology (London) $153,331-349$.

GORDON, G. and SEED, W. A. (1961). An investigation of nucleus gracilis in the cat by antidromic stimulation. Journal of Physiology (London) 155, 589-601.

GRAYBIEL, A. M. (1972). Some fiber pathways related to the posterior thalamic region in the cat. Brain, Behavior and Evolution 6, 363-393.

GROENEWEGEN, H. J., BOESTEN, A. J. P. and VOOGD, J. (1975). The dorsal column nuclear projections to the nucleus ventralis posterior lateralis thalami and the inferior olive in the cat: an auto-radiographic study. Journal of Comparative Neurology 162, 505-518.

HAND, P. J. (1966). Lumbrosacral dorsal root termination in the nucleus gracilis of the cat. Journal of Comparative Neurology $126,137-156$

HAND, P. J. and VAN WINKLE, T. (1975). Cuneothalamic projections of the cat. Anatomical Record 181, 371.

HOSOBUCHI, Y., ADAMS, J. E. and WEINSTEIN, P. R. (1972). Preliminary percutaneous dorsal column stimulation prior to permanent implantation. Journal of Neurosurgery 37, 242.

KELLER, J. H. and HAND, P. J. (1970). Dorsal root projections to nucleus cuneatus of the cat: Brain Research 20, 1-17.

KITAI, S. T. and WEINBERG, J. (1968). Tactile discrimination study of the dorsal column-medial lemniscal system and spino-cervicothalamic tract in cat. Experimental Brain Research 6, 234-246.

KRUGER, L. (1973). The Dorsal Column System of the Spinal Cord: Its Anatomy, Physiology, Phylogeny, and Sensory Function. UCLA Brain Information Service, Los Angeles, pp. 1-179. 
KUHN, R. A. (1949). Topographical pattern of cutaneous sensibility in the dorsal column nuclei of the cat. Transactions of the American Neurological Association 74, 227-230.

KUYPERS, H. G. J. M. and TUERK, J. D. (1964). The distribution of the cortical fibers within the nuclei cuneatus and gracilis of the cat. Journal of Anatomy 98, 143-162.

LARSON, S. J., SANCES, A. Jr., RIEGEL, D. H., MEYER, G. A., DALLMAN, D. E. and SWIONTEK, T. (1974). Neurophysiological effects of dorsal column stimulation in man and monkey. Journal of Neurosurgery 41, 214-223.

LEVITT, M. and SCHWARTZMAN, R. (1966). Spinal sensory tracts and two-point tactile sensitivity. Anatomical Record 54, 377.

LUND, R. D. and WEBSTER, K. E. (1967). Thalamic afferents from the dorsal column nuclei. An experimental anatomical study in the rat. Journal of Comparative Neurology $130,301-312$.

LUNDBERG, A. and NORRSELL, U. (1960). Spinal afferent pathway of the tactile placing reaction, Experientia 16, 123.

LYNN, B. (1975). Somatosensory receptors and their CNS connections. Annual Review of Physiology 37, 105-129.

McCOMAS, A. J. (1963). Responses of the rat dorsal column system to mechanical stimulation of the hindpaw. Journal of Physiology (London) 166, 435-448.

MELZACK, R. and BRIDGES, J. A. (1971). Dorsal column contributions to motor behavior. Experimental Neurology 33, 53-68.

MELZACK, R. and SOUTHMAYD, S. E. (1974). Dorsal column contributions to anticipatory motor behavior. Experimental Neurology 42, 274-281.

MOUNTCASTLE, V. B. and DARIAN SMITH, I. (1968). Neural mechanisms in somesthesia. In "Medical Physiology", volume 2, edited by V. B. Mountcastle, C. V. Mosby, St. Louis, pp. 1372-1423.

MOUNTCASTLE, V. B., LYNCH, J. C., GEORGOPOULOS, A., SAKATA, H. and ACUNA, C. (1975). Posterior parietal association cortex of the monkey: command functions for operations within extrapersonal space. Journal of Neurophysiology 38, 871-908.

MYERS, D. A., HOSTETTER, G., BOURASSA, C. M. and SWETT, J. (1975). Dorsal columns in sensory detection. Brain Research 70, 350-352.

NASHOLD, B., SOMJEN, G. and FRIEDMAN, H. (1972). Paresthesias and EEG potentials evoked by stimulation of the dorsal funiculi in man. Experimental Neurology 36, 273-287.

NORRSELL, U. (1966). The spinal afferent pathway of conditioned reflexes to cutaneous stimuli in the dog. Experimental Brain Research 2, 269-282.
O'KEEFE, J. and GAFFAN, D. (1971). Response properties of units in dorsal column nuclei of freely moving rats. Changes as a function of behavior. Brain Research 31, 374-375.

PERL, E. R., WHITLOCK, D. G. and GENTRY, J. R. (1962). Cutaneous projection to second-order neurons of the dorsal column system. Journal of Neurophysiology 25, 337-358.

PETIT, D. (1972). Postsynaptic fibers in the dorsal columns and their relay in the nucleus gracilis. Brain Research 48, 380-384.

PETIT, D. and BURGESS, P. P. (1968). Dorsal column projection of receptors in cat hairy skin supplied by myelinated fibers. Journal of Neurophysiology 31, 849-855.

RINVIK, E, and WALBERG, F. (1975). Studies on the cerebellar projections from the main and external cuneate nuclei in the cat by means of retrograde axonal transport of horseradish peroxidase. Brain Research 95, 371-381.

ROSEN, I. (1969). Localization in caudal brain stem and cervical spinal cord of neurons activated from forelimb group I afferents. Brain Research 16, 55-71.

ROSEN, I. and SJOLUND, B. (1973). Organization of Group I activated cells in the main and external cuneate nuclei of the cat: Identification of muscle receptors. Experimental Brain Research 16, 221-237.

RUSTIONI, A. (1973). Non-primary afferents to the nucleus gracilis from the lumbar cord of the cat. Brain Research 51, 81-95.

RUSTIONI, A. (1974). Non-primary afferents to the cuneate nucleus in the brachial dorsal funiculus of the cat. Brain Research $75,247-259$

RUSTIONI, A. and MACCHI, G. (1968). Distribution of dorsal root fibers in the medualla oblongata of the cat. Journal of Comparative Neurology 134, 113-126.

RUSTIONI, A. and MOLENAAR, I. (1975). Dorsal column nuclei afferents in the lateral funiculus of the cat: distribution pattern and absence of sprouting after chronic deafferentation. Experimental Brain Research $23,1-12$

SCHWARTZ, A. S., EIDELBERG, E., MARCHOK, P. and AZULAY, A. (1972). Tactile discrimination in the monkey after section of the dorsal funiculus and lateral lemniscus. Experimental Brain Research 37, 582-596.

SCHWARTZMAN, R. J. and BOGDONOFF M. D. (1968). Behavioral and anatomical analysis of vibration sensibility. Experimental Neurology 20, 43-51.

SCHWARTZMAN, R. J. and BOGDONOFF, M. D. (1969). Proprioception and vibration sensibility discrimination in the absence of the posterior columns. Archives of Neurology (Chicago) 20, 349-353.

SEMMES, J. (1969). Protopathic and epicritic sensation: A reappraisal. In "Contributions to Clinical Neuropsychology", edited by A. L. Benton, Aldine, Chicago, pp. 142-171.

SEMMES, J. (1973). Somesthetic effects of damage to the central nervous system. In "Handbook of Sensory Physiology," volume 2, Somatosensory system edited by A. Iggo, Springer-Verlag, Berlin, pp. 719-742.

TABER, E. (1961). The cytoarchitecture of the brain stem of the cat. I. Brain stem nuclei of the cat. Journal of Comparative Neurology 116, 27-70.

TAPPER, D. N. (1970). Behavioral evaluation of the tactile pad receptor system in hairy skin of the cat. Experimental Neurology $26,447-459$.

TOWE, A. L. (1973). Somatomsensory cortex: descending influences on ascending systems. In "Handbook of Sensory Physiology", volume 2, Somatomsensory system edited by A. Iggo, Springer-Verlag, Berlin, pp. 701-718.

UDDENBERG, N. (1968). Differential localization in dorsal funiculus of fibers originating from different receptors. Experimental Brain Research 4, 367-376.

VIERCK, C. J. Jr. (1966). Spinal pathways mediating limb position sense. Anatomical Record 154, 437.

VIERCK, C. J. Jr. (1973). Alterations of spatiotactile discrimination after lesions of primate spinal cord. Brain Research 58 , 69-79.

VIERCK, C. J. Jr. (1974). Tactile movement detection and discrimination following dorsal column lesions in monkeys. Experimental Brain Research 20, 331-346.

VIERCK, C. J. Jr., HAMILTON, D. M. and THORNBY, J. I. (1971). Pain reactivity of monkeys after lesions to the dorsal and lateral columns of the spinal cord. Experimental Brain Research 13, 140-158.

WALL, P. D. (1970). The sensory and motor impulses travelling in the dorsal column toward cerebral cortex. Brain 93, 505-524.

WALL, P. D. and DUBNER, R. (1972). Somatosensory pathways. Annual Review of Physiology 34, 315-336.

WALL, P. D. and EGGER, M. D. (1971). Formation of new connexions in adult rat brains after partial deafferentation. Nature 232, 542-545.

WHITSEL, B. L., PETRUCELLI, L. M., HA, H. and DREYER, D. A. (1972. The resorting of spinal afferents as antecedent to the body representation in the poscentral gyrus. Brain, Behavior and Evolution 5, 303-341.

WILLIS, W. D., MAUNZ, R. A., FOREMAN, R. D. and COULTER, J. D. (1975). Static and dynamic responses by spinothalamic tract neurons to mechanical stimuli. Journal of Neurophysiology 38, 587-600.

WINTER, D. L. (1965). N. gracilis of cat. Functional organization and corticofugal effects. Journal of Neurophysiology 28 , 48-70. 